\title{
Insulin induced lipodystrophy
}

\author{
PRATHIMA KADIYALA ${ }^{1}$, SHERNAZ WALTON², THOZHUKAT SATHYAPALAN ${ }^{3}$
}

\begin{abstract}
Insulin induced lipoatrophy and, more commonly, lipohypertrophy are dermatological complications of insulin therapy. Lipoatrophy is becoming less common with the advent of newer insulin analogues; however, lipohypertrophy is still prevalent. Whilst an immunological mechanism is postulated for lipoatrophy, direct local anabolic action of insulin is postulated for lipohypertrophy. Other factors which are implicated are the duration of diabetes, the number of insulin injections, re-use of needles and pen devices. The best current preventative and therapeutic strategies for insulin induced lipohypertrophy include rotation of injection sites with each injection and non-reuse of needles. Topical dexamethasone injections have been tried for the management of insulin induced lipoatrophy. It is important that these complications are recognised and managed appropriately. Insulin absorption from these sites is unpredictable and can lead to erratic glycaemic levels and unpredictable hypoglycaemic attacks. This article raises awareness of the possibility of insulin induced lipodystrophy as a cause of poor glycaemic control.
\end{abstract}

Br J Diabetes Vasc Dis 2014;14:131-133

Key words: insulin, lipoatrophy, lipohypertrophy,

dexamethasone, glycaemia

\section{Introduction}

Lipodystrophies are a heterogeneous group of disorders characterised by abnormal distribution of body fat which can be genetic or acquired and also can have a generalised distribution or a more localised (partial) distribution. Insulin induced lipodystrophy is an acquired partial lipodystrophy. ${ }^{1}$ Lipohypertrophy and lipoatrophy are two main inter-related but distinct derma-

Department of Dermatology, Harrogate District Foundation Trust, Harrogate, UK

2 Department of Dermatology, Hull and East Yorkshire Hospitals NHS Trust and Hull York Medical School, Hull, UK

3 Department of Academic Diabetes, Endocrinology and Metabolism, University of Hull and Hull and East Yorkshire Hospitals NHS Trust, UK

Address for correspondence: Dr Shernaz Walton

Department of Dermatology, Hull and East Yorkshire Hospitals NHS

Trust and Hull York, Medical School, Hull, UK

Tel: $+44(0) 1482816623$

E-mail: shernaz.walton@hey.nhs.uk

http://dx.doi.org/10.15277/bjdvd.2014.036

\author{
Abbreviations and acronyms \\ CSII continuous subcutaneous insulin infusion \\ IgM Immunoglobulin $\mathrm{M}$
}

tological complications of subcutaneous insulin injections. Of these, lipohypertrophy is a much more common complication than lipoatrophy. The prevalence of insulin induced lipohypertrophy is approximately $25-30 \%$ in patients with type 1 diabetes and $<5 \%$ in patients with type 2 diabetes with subcutaneous insulin treatment. ${ }^{2}$ On the other hand, insulin induced lipoatrophy, though very rare, still continues to be reported. ${ }^{3,4}$ Since the introduction of insulin analogues, the incidence of lipoatrophy has fallen in recent years from $25-55 \%$ with treatment with non-purified bovine or porcine insulin preparations ${ }^{5}$ to around $3.6 \%$ with treatment with recombinant human insulin and analogues. ${ }^{6}$

\section{Diagnosis}

\section{Clinical findings}

Lipohypertrophic areas usually present as soft dermal nodules like lipomas or fibrocollagenous scar tissue within the skin ${ }^{7}$ and can vary in size from golf balls to an orange ${ }^{8}$ (Figure 1). When large areas are involved, the appearance can be unsightly. Initial skin changes can be subtle and manifest only as thickening of skin. This can be easily missed by visual inspection and so areas should be palpated. It is recommended that, in order to feel subtle skin thickening, the hand should be stroked firmly in a sweeping motion rather than using traditional techniques of light and deep palpation. ${ }^{8}$ Most common areas involved are on either side of the umbilicus and mid thigh as these are commonly used sites for injection and are easily reached and convenient for patients. Lipoatrophic areas, on the other hand, present as localised areas of fat loss and can be cosmetically unsightly (Figure 2).

\section{Causes}

Lipohypertrophy is thought to be the direct anabolic effect of insulin on local skin leading to fat and protein synthesis ${ }^{9}$ and hence this is observed even with recombinant insulin preparations and continuous insulin infusion pumps. This complication occurs because of repeated injections at the same site. As these areas are relatively painless, patients tend to inject in the same area again and again rather than move to a new painful site. Other possible risk factors associated are type 1 diabetes due to longer duration of insulin therapy, high number of insulin 
Figure 1. Insulin lipohypertrophy on the thigh of a patient with diabetes on subcutaneous insulin treatment

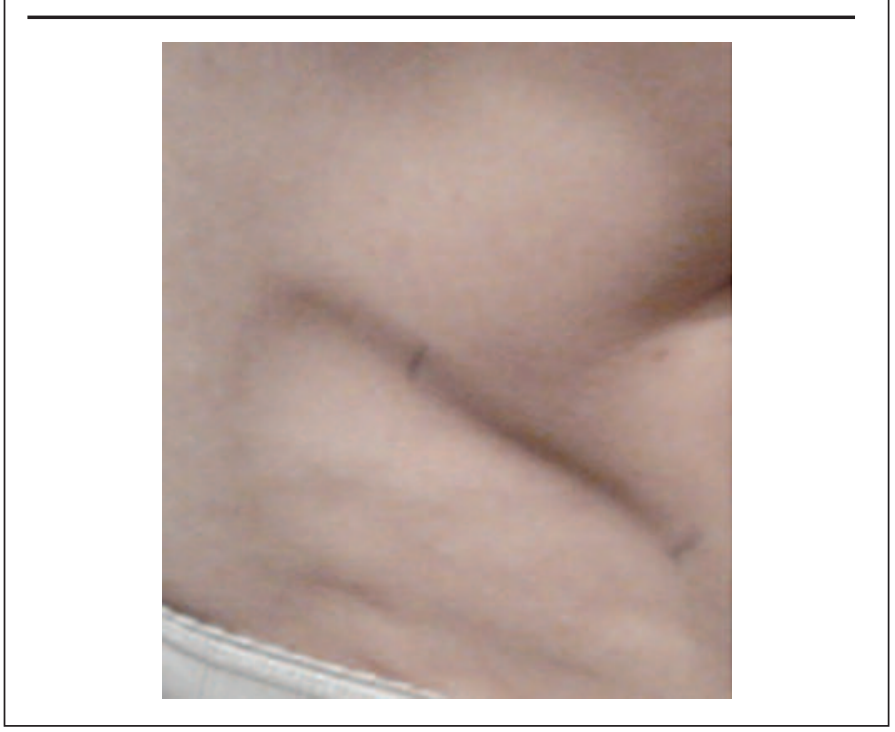

Figure 2. Insulin lipoatrophy on the arm of a patient with diabetes on subcutaneous insulin treatment

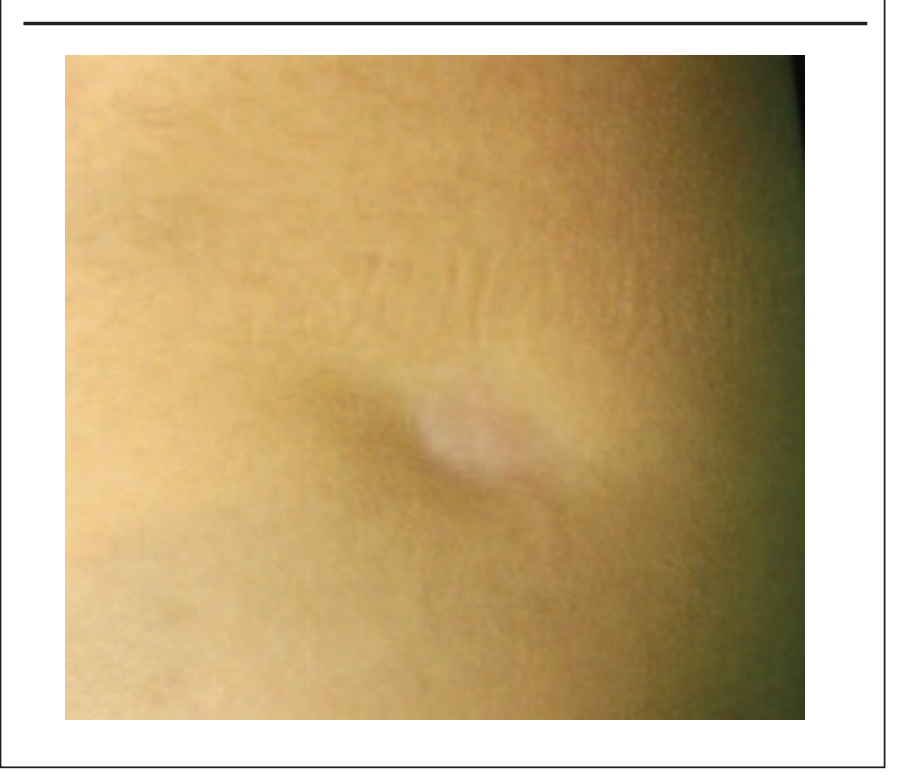

injections, reuse of needles with a significant increase if used more than five times and use of pen devices. Development of insulin antibodies is also suggested as a possible underlying mechanism. ${ }^{10,11}$

Lipoatrophy is considered an immune mediated inflammatory response. Although it was much commoner with bovine and porcine insulin, it still remains a complication of insulin therapy irrespective of the insulin source (animal, recombinant, or analogue) and the mode of administration. ${ }^{12,13}$ The respective exposition to the analogues lispro, aspart, glargine and detemir prior to lipoatrophy development varies between 4 weeks and 2 years. ${ }^{14}$ Lipoatrophy can also occur with CSII therapy ${ }^{15}$ and more than one type of insulin analogue in the same patient. ${ }^{16}$ Repeated use of the same insulin injection site and multiple usage of the same pen needle increases the risk of lipoatrophy. ${ }^{12}$

Atrophy results from the local formation of complexes between injected antigen and circulating antibody with activation of complement and infiltration of inflammatory cells. This is similar to the classical Arthus immunological reaction where atrophy happens because of local deposition of immune complexes formed from injected antigen and circulating antibodies followed by an acute vasculitis. Local overproduction of cytokines and tumour necrosis factor from mast cells may inhibit adipocyte differentiation. Anti-insulin antibodies were thought to be strongly associated with the development of skin atrophy. ${ }^{10}$ Although patients may describe transient red nodules or urticarial lesions soon after commencing insulin injections, the clinical appearance of lipoatrophy is notable for its lack of inflammatory features. This contrast with the Arthus reaction is probably due to the considerable difference in antigenicity between whole horse serum used in the classical Arthus experiments and re-crystallised insulin preparations and to different dose and frequency of injections. ${ }^{10}$

\section{Histopathology}

Histology from lipohypertrophic areas shows an increase in the size of fat cells, nearly double the volume compared with the fat cells from surrounding normal skin. Discrete areas of small adipocytes at the periphery possibly represent proliferation. ${ }^{17}$ The appearance of collagenous scar tissue with hypovascular collagen and bland looking fibroblasts has also been described. ${ }^{7}$

Histology from lipoatrophic areas shows degenerative changes in adipose tissue with deposition of IgM, complement ${ }^{3}$ or fibrin-fibrinogen in dermal blood vessels at the edges of these sites. ${ }^{18}$ This suggests an immune mechanism, further supported by the finding of a much higher insulin-binding capacity in patients with lipoatrophy. ${ }^{10}$

\section{Management}

It is important that these complications are recognised and managed appropriately. Insulin absorption from these sites is unpredictable and can lead to erratic glycaemic levels and unpredictable hypoglycaemic attacks. 2,12 When large areas are involved, it can be cosmetically unsightly and socially embarrassing for patients.

Injection sites should be examined at least annually by a health care professional for possible lipohypertrophy or lipoatrophy. Individuals should also be taught to examine their own injection sites and how to detect lipohypertrophy. ${ }^{8,19}$ Individuals should be advised not to inject into areas of lipohypertrophy until abnormal tissue returns to normal, which will take several months or even years. Switching injections from areas of lipohypertrophy to normal tissue often requires a decrease in the dose of insulin injected. The amount of change varies from one individual to another and should be guided by frequent blood glucose measurements. The best current preventative and therapeutic strategies for lipohypertrophy include rotation of injection 


\section{Key messages}

- Lipodystrophy due to insulin therapy manifests as lipohypertrophy or lipoatrophy

- With the advent of new purified and recombinant human insulins, lipoatrophy seems to be largely extinct but lipohypertrophy continues to occur as a complication of insulin therapy

- It is important that these skin changes are recognised, as insulin absorption can be altered leading to poor glycaemic control

sites with each injection and non-reuse of needles. ${ }^{19}$

Changing injection sites helps in preventing development of lipohypertrophy. Patients should be educated regarding proper injection techniques and rotating injection sites. Patients should be taught self examination for early recognition of skin changes and to avoid these areas. Clinicians should examine the skin annually as advised by Diabetes UK. Changing insulin to rapid acting humanised insulin has been shown to decrease this side effect as adipocytes are in contact with insulin for short periods and thus local lipogenic effects are minimised. ${ }^{20}$ If conservative steps fail, then liposuction is an effective alternative.

Changing or rotating the site of insulin injection and changing type of insulin were traditional approaches to prevent further lipoatrophy. Switching to $\mathrm{CSII}^{2,12}$ and/or short acting insulin analogues are alternative methods. These lesions can sometimes spontaneously regress, but use of small amounts of dexamethasone along with insulin injections was found to be beneficial. ${ }^{21}$ Injection of dexamethasone into the lipoatrophic lesions resulted in return of subcutaneous fat tissue in a few cases. 22,23

\section{Conflict of interest None Funding sources None}

\section{References}

1. Garg A. Clinical review\#: Lipodystrophies: genetic and acquired body fat disorders. JCEM 2011;96:3313-25.

2. Richardson T, Kerr D. Skin-related complications of insulin therapy. Am J Clin Dermatol 2003;4(10):661-7. http://dx.doi.org/10.2165/00128071-200304100-00001

3. Hussein SF, Siddique H, Coates P, et al. Lipoatrophy is a thing of the past, or is it? Diabet Med 2007;24:1470-2. http://dx.doi.org/10.1111/j.1464-5491.2007.02300.x

4. MaX, Lv H, Li Q, et al. Severe lipoatrophy with insulin in type 1 diabetes. J Dermatol 2012;39(6):578-9.

http://dx.doi.org/10.1111/j.1346-8138.2011. 01415.x

5. Schernthaner G. Immunogenicity and allergenic potential of animal and human insulins. Diabetes Care 1993;16 Suppl 3:155-65.
6. Sackey AH. Images in clinical medicine. Injection-site lipoatrophy. NEJM 2009;361:e41. http://dx.doi.org/10.1056/NEJMicm0808275

7. Wallymahmed ME, Littler $\mathrm{P}$, Clegg $\mathrm{C}$, et al. Nodules of fibrocollagenous scar tissue induced by subcutaneous insulin injections: a cause of poor diabetic control. Postgrad Med J 2004;80:732-3.

http://dx.doi.org/10.1136/pgmj.2004.019547

8. Hambridge K. The management of lipohypertrophy in diabetes care. $\mathrm{Br}$ J Nurs 2007;16:520-4.

http://dx.doi.org/10.12968/bjon.2007.16.9.23428

9. Hauner H, Stockamp B, Haastert B. Prevalence of lipohypertrophy in insulin-treated diabetic patients and predisposing factors. Exp Clin Endocrinol Diabetes 1996;104(2):106-10. http://dx.doi.org/10.1055/s-0029-1211431

10. Reeves WG, Allen BR, Tattersall RB. Insulin-induced lipoatrophy: evidence for an immune pathogenesis. BMJ 1980;280:1500-03. http://dx.doi.org/10.1136/bmj.280.6230.1500

11. Raile K, Noelle V, Landgraf $R$, et al. Insulin antibodies are associated with lipoatrophy but also with lipohypertrophy in children and adolescents with type 1 diabetes. Exp Clin Endocrinol Diabetes 2001;109:393-6. http://dx.doi.org/10.1055/s-2001-18991

12. Radermecker RP, Pierard GE, Scheen AJ. Lipodystrophy reactions to insulin: effects of continuous insulin infusion and new insulin analogs. Am J Clin Dermatol 2007:8:21-8. http://dx.doi.org/10.2165/00128071-200708010-00003

13. Atlan-Gepner C, Bongrand P, Farnarier $C$, et al. Insulin-induced lipoatrophy in type I diabetes. A possible tumor necrosis factor-alphamediated dedifferentiation of adipocytes. Diabetes Care 1996;19:12835. http://dx.doi.org/10.2337/diacare.19.11.1283

14. Holstein A, Stege H, Kovacs P. Lipoatrophy associated with the use of insulin analogues: a new case associated with the use of insulin glargine and review of the literature. Expert Opin Drug Safety 2010;9:225-31. http://dx.doi.org/10.1517/14740330903496402

15. Chantelau EA, Praetor R, Praetor J, et al. Relapsing insulin-induced lipoatrophy, cured by prolonged low-dose oral prednisone: a case report. Diabetol Metab Syndr 2011;3:33. http://dx.doi.org/10.1186/1758-5996-3-33

16. Lopez $X$, Castells M, Ricker A, et al. Human insulin analog--induced lipoatrophy. Diabetes Care 2008;31:442-4. http://dx.doi.org/ 10.2337/dc07-1739

17. Fujikura J, Fujimoto $M$, Yasue $S$, et al. Insulin-induced lipohypertrophy: report of a case with histopathology. Endocr J 2005;52:623-8. http://dx.doi.org/10.1507/endocrj.52.623

18. Wright $A D$, Walsh $C H$, Fitzgerald $M G$, et al. Very pure porcine insulin in clinical practice. BMJ 1979;1:25-7. http://dx.doi.org/10.1136/bmj.1. 6155.25

19. Frid A, Hirsch L, Gaspar R, et al. New injection recommendations for patients with diabetes. Diabetes Metab 2010;36 Suppl 2:S3-18. http://dx.doi.org/10.1016/S1262-3636(10)70002-1

20. Roper NA, Bilous RW. Resolution of lipohypertrophy following change of short-acting insulin to insulin lispro (Humalog). Diabet Med 1998;15:1063-4.

http://dx.doi.org/10.1002/(SICI)1096-9136(1998120)15:12<1063::AIDDIA706>3.0.CO;2-V

21. Kumar O, Miller L, Mehtalia S. Use of dexamethasone in treatment of insulin lipoatrophy. Diabetes 1977;26:296-9. http://dx.doi.org/10.2337/diab.26.4.296

22. Whitley TH, Lawrence PA, Smith CL. Amelioration of insulin lipoatrophy by dexamethasone injection. JAMA 1976;235:839-40. http://dx.doi.org/10.1001/jama.1976.03260340045021

23. Ramos AJ, Farias MA. Human insulin-induced lipoatrophy: a successful treatment with glucocorticoid. Diabetes Care 2006;29:926-7. http://dx.doi.org/10.2337/diacare.29.04.06.dc06-0004 